\title{
Der Kubifator.
}

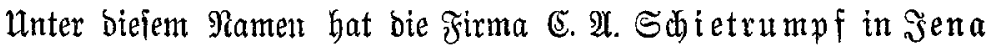
Das nachitebend abgebildete Snitrument zu rajcher Beftimmung bes Subik= inhaltes vermeffener Stämme und 2lbidintitte tonftruiert und in ben Sandel gebradt.

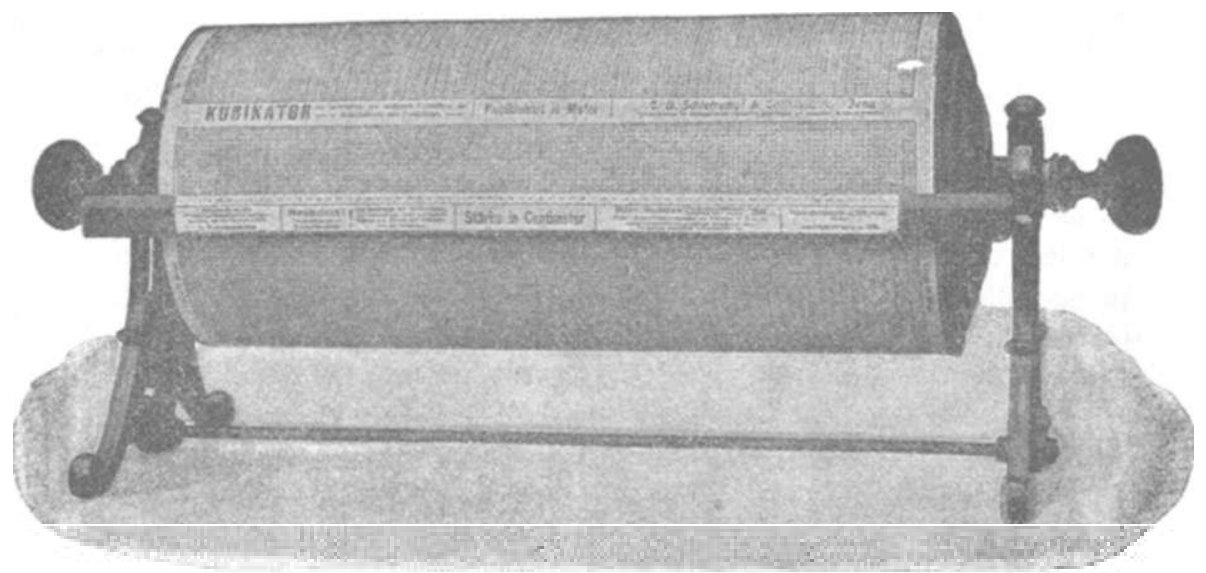

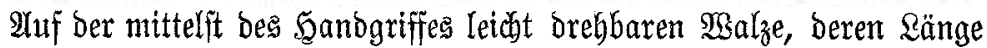
$48 \mathrm{~cm}$, Deren Durcbmeffer $14 \mathrm{~cm}$ beträgt, find beiberjeitig bie Stamm= längen, abgeituft nach $0,2,0,4,0,5,06,0,8$ und ganzen Metern an= gegeben, auf ben dazmijhen liegenben Felbern bie Rubifinbalte nach 2 Dez̧imalftellen, während bie bavorliegende Sdjiene bie Stammittärfen in Eentimetern trägt. Durd) Einftellung ber entfpredbenden Stamm= längenzahl an bie obere Schienentante kann man jofort über ber Stamm= ftärfenzabl ber Sdjienenfante ben zugehörigen Subifinhalt ablejen.

Der $\mathfrak{B e r t}$ ber Sorrichtung liegt in ber Sinnedigfeit und $\mathfrak{B} e q u e m=$ lichleit, nut meld)er biejelbe gegenüber Den übliden Rubierungatabellen

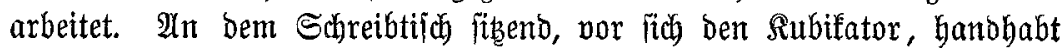
man biefen mit ber linfen \$ूano, mit der redten bie abgelefenen 8 ahlen in bas Nummernbuth eintragent; bei einiger Alufmerffamteit fino Эrr tïmer ausgeichloffen.

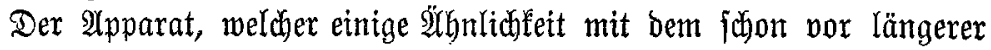
Zeit fomitruterten, ben gleichen Zwed verfolgenben "Eubug" zeigt, loftet:

$\mathfrak{N}$ r. 1. Mit Einteilung für Stãmme von 0,2 bis $20 \mathrm{~m}$ Ränge und Durchmejiern von $6-75 \mathrm{~cm}$. . . . . . . 22,50 $\mathscr{M}$

" 2. Mit Einteilung für Stämme von $0,1-20 \mathrm{~m}$ Ränge (iteigento um je 0,1 m \&änge) und Durctimefiern von $6-75 \mathrm{~m} 27,50 \mathscr{M}$

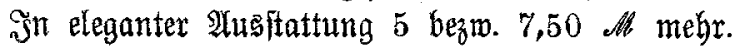

